\title{
La piedra imán: de Lucrecio a Claudiano; de la ciencia a la mitología
}

\author{
Liliana Pégolo \\ pegolabe@gmail.com \\ Universidad de Buenos Aires, Argentina \\ Camilo Abecian \\ camilo.abecian@gmail.com \\ Universidad Tecnológica Nacional, Argentina
}

Recepción: 14 Febrero 2020

Aprobación: 02 Junio 2020

Publicación: 02 Noviembre 2020

Cita sugerida: Pégolo, L. y Abecian, C. (2020). La piedra imán: de Lucrecio a Claudiano; de la ciencia a la mitología. Auster, (25), e062. https://doi.org/10.24215/23468890e062

\begin{abstract}
Resumen: En De rerum natura VI, en el contexto de las "maravillas" naturales, Lucrecio analiza la fisiología del magnetismo (VI.906-920) y sus efectos (VI.998-1099). Claudio Claudiano, cinco siglos después, resignifica las argumentaciones del poeta romano sobre la piedra imán, en un poema de los Carmina minora. A diferencia de Lucrecio, Claudiano resigna las conclusiones científicas para abocarse a la descripción de la inexplicable atracción que ejerce la piedra sobre el hierro. A partir de lo señalado, la comunicación pretende analizar los esfuerzos lucrecianos por explicar el magnetismo y las transformaciones operadas por Claudiano, quien fusiona hábilmente la ciencia y la poesía.
\end{abstract}

Palabras clave: Lucrecio, Epicureísmo, Magnetismo, Claudiano, Alegoría.

\begin{abstract}
In De rerum natura VI, in the context of natural "wonders", Lucretius analyzes the physiology of magnetism (VI.906-920) and its effects (VI.998-1099). Claudius Claudianus, five centuries later, resignifies the arguments of the Roman poet on the imam stone, in a poem by the Carmina minora. Unlike Lucretius, Claudianus resigns the scientific conclusions to focus on the description of the inexplicable attraction that the stone exerts on iron. Based on the above, the communication aims to analyze Lucretian efforts to explain the magnetism and transformations operated by Claudianus, who skillfully fuses science and poetry.
\end{abstract}

Keywords: Lucretius, Epicureanism, Magnetism, Claudianus, Allegory.

\section{CONSIDERACIONES PRELIMINARES}

De rerum natura ${ }^{1}$ representa un sistema epistemológico de metodología científica cuyo autor, Tito Lucrecio Caro (ca. 99-54 a.C.), procuró deshacer los vincula que sujetan al hombre a las concepciones mítico-religiosas, disertando "sobre el principio elevado del cielo y de los dioses" y "los elementos primordiales de las cosas" (DRN., I, 54-55: de summa caeli ratione deumquel disserere [...] et rerum primordia). Sus esfuerzos, también vinculados a los de los filósofos presocráticos ${ }^{2}$ —cuya tradición fisiológica se inscribe bajo la denominación períphýseos-, residen en la exposición de la filosofía epicúrea por medio de la cual se buscó alcanzar la imperturbabilidad del ánimo o ataraxía, a partir de la comprensión del universo y de sus leyes particulares. 
Precisamente, Epicuro de Atenas (341-270 a.C.), acerca del cual Lucrecio consideraba "que [...] vertió todas las cosas de su boca plena de verdad"3(DRN., VI, 6: omnia veridico qui [...] ex ore profudit), fue quien organizó esta doctrina sobre la base de cuatro principios reguladores, conocidos como tetraphármakono "cuadrifármaco", con los que procuró liberar a la humanidad de errores tales como el temor a los dioses, el temor a la muerte, el exceso de bienes y el límite de los males y los dolores. ${ }^{4}$ Asimismo, según afirma Farrington, el epicureísmo, surgido hacia el año 312 a.C., contó entre sus premisas generales la de proporcionar "al hombre una norma de conducta en su vida mientras el mundo era presa de una gran convulsión social". 5

Con un espíritu liberador semejante, Lucrecio resignificó estos principios en 'clave romana', con el objeto de entregar a sus contemporáneos un instrumento que diera sosiego a la incertidumbre de sus ánimos, abatidos por las guerras sociales y partidarias. Consciente de que ninguno antes que él, en el ámbito de la literatura latina, había recorrido "los inaccesibles lugares de las Piérides" (DRN., I, 926: avia Pieridum [...] loca), Lucrecio persistió en la necesidad de dar fin "al terror y a las tinieblas del ánimo" (DRN., VI, 39: terrorem animi tenebrasque). En contra de la superstición religiosa, Epicuro había expuesto, en su momento, su oposición a la restauración de los "dioses-estrellas" — característicos de la religión política platónicoaristotélica- y a la adivinación astrológica, por lo cual Lucrecio lo exalta librando batallas a la manera de los héroes y las divinidades ${ }^{7}$ y alcanzando, finalmente, "la victoria" que iguala a los sabios "con el cielo" ( $D R N$., I, 79: nos exaequat victoria caelo). En consonancia con esto, De rerum natura exhibe el análisis de numerosos motivos atinentes a la cosmología, las percepciones sensoriales, las enfermedades, los eclipses, la evolución del hombre e, incluso, la piedra imán. Lucrecio la incluyó en el contexto de un conjunto de 'maravillas' que desafían la inteligencia humana, atendiendo no solo a las características generales del denominado magnes (DRN., VI, 906-920), sino también a los efectos del magnetismo (DRN., VI, 998-1099).

Por otra parte, casi cinco siglos después de la composición de De rerum natura, Claudio Claudiano (ca. 370-405 d.C.) - poeta de origen alejandrino asimilado a la corte del emperador Honorio- recurrió al texto lucreciano con el objeto de exaltar las peculiaridades del magneto en uno de los breves poemas de sus Carmina minora. ${ }^{8}$ A diferencia de Lucrecio, Claudiano se vale del recurso de la paradoja para interrogarse acerca de un objeto carente de belleza que despertaba la admiración de los hombres. ${ }^{9}$ El texto del poeta tardío, que comprende cincuenta y siete hexámetros, no persigue la argumentación científica de su antecesor sino despertar el deslumbramiento ante lo inexplicable y lo maravilloso, ya que la descripción de cómo la piedra imán atrae el hierro es desplazada al ámbito de lo mítico: en este contexto, Venus y Marte, alegorizados, representan respectivamente la atracción magnética y la férrea tenacidad del metal.

Finalmente, en relación con lo dicho hasta aquí, cabe señalar que el presente trabajo procurará demostrar cuáles son las características y los efectos de la piedra imán, según el sistema epicúreo-lucreciano, y analizar el diálogo que se establece con el texto de Claudiano, quien se mostró como un hábil experimentador en la fusión de la ciencia y la ficción poética. ${ }^{10}$

\section{Características del magnetismo y Sus efectos en DE RERUM NatURA}

En particular, es en el Libro VI donde Lucrecio se dedicó a iluminar las razones en torno a los fenómenos meteorológicos para que los hombres desestimaran la creencia de que son un producto de la iracundia divina. Al respecto, afirmaba: [Quorum operum causas nulla ratione videre/ possunt ac fieri divino numine rentur] (DRN., VI, 90-91: [No pueden ver, por ninguna razón, las causas de estas/ obras y creen que suceden a causa de un poder divino]). En cuanto al saber meteorológico, Serres señala que la Meteorología, marginada generalmente de la historia de la ciencia, ${ }^{11}$ se encontraba entre los intereses de los fisiólogos jónicos, de Platón, de Aristóteles y del propio Epicuro. ${ }^{12}$ Por otra parte, en el marco religioso de la adivinación romana, los omina 
y los auspicia estaban dirigidos a desentrañar, entre otros presagios, las voces del trueno y la visualización de los relámpagos y de los rayos, conocida esta última con el nombre de keraunoscopía. ${ }^{13}$ Por lo tanto, no ha de extrañar que, entre los argumentos del último libro, Lucrecio estima que "deben cantarse las tormentas y los rayos luminosos, / qué hacen y por qué causa siempre se producen" (DRN., VI, 84-85 sunt tempestates et fulmina clara canenda,/ id faciant et qua de causa cumque ferantur).

También en el Libro VI —el de los meteoros_- ${ }^{14}$ denominado por Serres "el libro de las turbulencias", 15 se exponen otros fenómenos explicables por el principio de que 'todo fluye continuamente', ${ }^{16}$ tales como las trombas marinas, las corrientes de lava del Etna, los movimientos sísmicos, las corrientes del mar, las de las fuentes, ríos y pozos. Asimismo, insistiendo desde el comienzo de este libro en que la ignorancia de las causas fenoménicas es lo que lleva a los hombres a someterse a los dioses, ${ }^{17}$ Lucrecio se ocupa de todo aquello que despierta el asombro y la admiración, tal como ocurre con la piedra imán, acerca de la cual sostiene que "los hombres se maravillan de esta piedra" (DRN., VI, 910: Hunc homines lapidem mirantur). No obstante, el miraculum, plausible de ser reducido al dominio de lo religioso por el desconocimiento, es entendido como parte de un 'acuerdo necesario' que rige entre los elementos naturales; por lo tanto

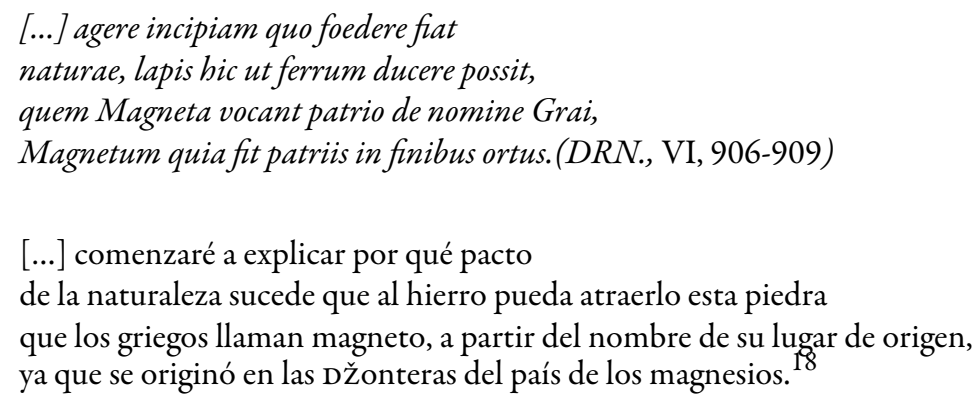

Si bien Lucrecio inició su explicación a partir de una referencia lexical y toponímica, retoma el concepto del viejo atomismo democríteo acerca de la avágke phýseos o "constricción natural"19 bajo el término foedus, el cual remite al orden de las relaciones sociales y políticas de la Roma contemporánea. Al respecto, Hellegouarc'h sostiene que, en general, foedus designa el pacto establecido entre dos personas o dos grupos sociales que se alían a través de la confianza recíproca (fides) e, incluso, también se lo utiliza en el marco de las relaciones que Roma llevaba a cabo con sus aliados o con los pueblos sometidos; pero, principalmente se recurre al término foedus en el dominio de los contratos entre órdenes sociales diferentes. ${ }^{20}$ En este sentido, Lucrecio entiende que la atracción dada entre ambos objetos resulta inviolable, puesto que está sustentada por un principio de mutua vinculación donde "las adherencias, las uniones, adaptaciones, incorporaciones y soldaduras" ${ }^{21}$ se definen por la especificidad local de los elementos que se justifican necesariamente.

Asimismo, Lucrecio recurre a procedimientos epicúreos — apropiados para una metodología científica de carácter empírico - con el fin de asegurar a la audiencia la adquisición de conocimientos valederos sobre fenómenos controversiales; ${ }^{22}$ en este caso, lo ejemplifica con un encadenamiento de anillos sostenidos por la adherencia del magneto:

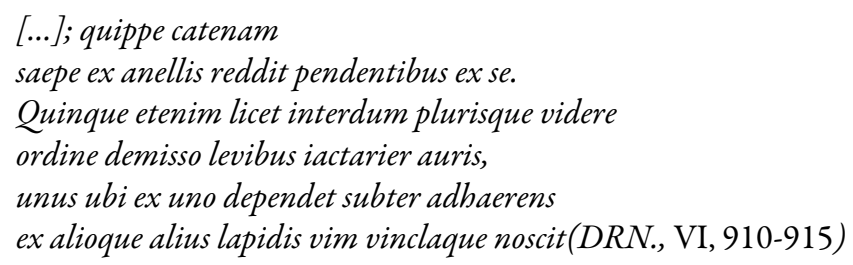


forma un encadenamiento de anillos que penden de ella.

Y de hecho se puede ver, en ocasiones, que cinco o más en orden sucesivo son empujados

por las leves brisas,

cuando uno pende de otro adhiriéndose por debajo,

y cada uno a su vez del otro conoce la fuerza vinculante de la piedra

Esta forma de ejemplificar le permite al poeta dar cuenta de la coherencia de su sistema teórico y, al igual que Epicuro, procura asirse, a través de argumentaciones retóricas, de datos tomados de la realidad sensible para homologarlos con la realidad "in-visible", "no perceptible" o res caeca. ${ }^{23}$ En consecuencia, exige la atención de su interlocutor para continuar con la exposición de su material, ya que la linealidad discursiva, — "the linear medium of communication”, como afirma Markovic ${ }^{24}$ — posibilitará aprehender la complejidad del universo:

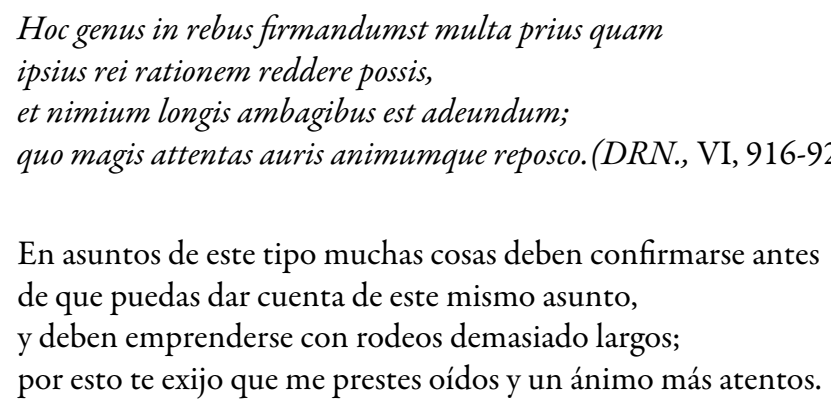

La explicación de lo que ocurre con la piedra imán no es excepcional, por el contrario, la naturaleza está constituida de elementos que fluyen necesariamente de manera continua a través del vacío, ${ }^{25}$ puesto que todo aquello que existe es materia y esta se encuentra en constante movimiento, por ello

Usque adeo omnibus ab rebus res quaeque fluenter

fertur et in cunctas dimittitur undique partis

nec mora nec requies interdatur ulla fluendi(DRN., VI, 931-934 [935, 930, 931])

Hasta tal punto cada cosa es llevada de manera fluida a partir

de todas las cosas y es enviada en todos los sentidos hacia todas partes

y no se concede demora ni reposo alguno en el fluir.

A su vez, Lucrecio afirma que todos los cuerpos producen emanaciones de distintos tipos y que pueden interactuar entre sí, según las diferentes sensibilidades y la naturaleza de la rarefacción, por lo tanto

Multa foramina cum variis sint reddita rebus,

dissimili inter se natura praedita debent

esse et habere suam naturam quaeque viasque.(DRN., VI, 981-983)

Ya que se asignaron muchos poros ${ }^{26}$ a cosas variadas,

deben haber sido dotadas de una naturaleza disímil

entre sí y tener cada una su naturaleza y sus conductos.

En consecuencia, establecidos estos preceptos (DRN., VI, 999: praeposta parata), Lucrecio deduce que el magnetismo es producto del flujo de los corpora, tanto de la piedra imán como del hierro, por lo cual ambos resultan ligados en el vacío "por medio de lazos no visibles" (DRN., VI, 1016: caecisque [...] compagibus). Los espacios liberados por la emanación de la piedra resultan ocupados por el aire que se encuentra en las 
porosidades del hierro, de forma tal que este aire arrastra a los objetos férreos "como el viento a las naves y a las velas” (VI, 1033 [1032]: quasi navem velaque ventus). Por último, el poeta concluye:

\author{
Hic igitur, penitus qui in ferrost abditus aer, \\ sollicito motu semper iactatur eoque \\ verberat anellum dubio procul et ciet intus(DRN., VI, 1037-1039)
}

En consecuencia, este aire, que está escondido profundamente

en el hierro, siempre es sacudido por un movimiento constante y por

eso, sin duda, azota al anillito y lo conmociona desde adentro;

En este punto, Lucrecio enumera diferentes experiencias con la piedra imán en relación con los llamados “anillos de Samotracia” (DRN., VI, 1044: Samothracia ferrea ${ }^{27}$ y con otros minerales, como los vasos de bronce o scaphia (DRN., VI, 1046) que no son atraídos magnéticamente, cosa que no debe llamar la atención si se argumenta siguiendo los procedimientos del sistema: Illud in his rebus mirari mitte,/ quod aestus non valet e lapide hoc alias impellere item res (DRN., VI, 1056-1057: En estas cuestiones, que no te asombre el hecho de que el flujo/ no tiene la fuerza para impulsar desde esta piedra, del mismo modo a otras cosas). En particular es lo que se produce con la madera, el oro y otros elementos que Lucrecio opta no mencionar para no extenderse en demasía y abusar de tan largos rodeos (DRN., VI, 1081: tam longis [...] ambagibus). Lo que sí insiste es en la existencia de una "unión óptima" que se produce cuando las cosas se encuentran "huecas", por lo cual pueden llenarse unas a otras, como sucede con la piedra imán y el hierro a causa de sus particulares texturas:

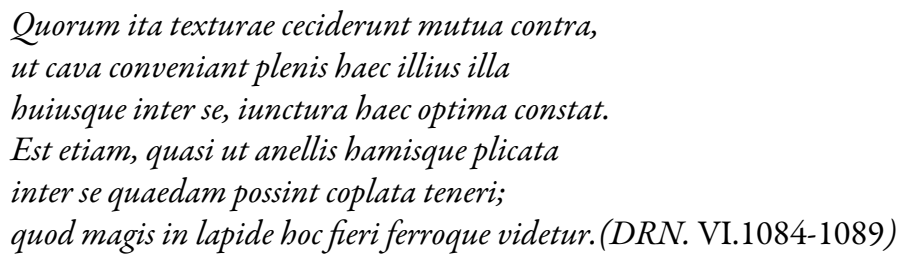

Las texturas de estas cosas se precipitan mutuamente en direcciones contrarias de manera tal que convergen entre sí, estas huecas con las llenas de aquel lado y aquellas (huecas), con las (llenas) de este otro; esta es la unión óptima. Sucede, también, que ciertas cosas pueden sostenerse plegadas entre sí, como si estuvieran entrelazadas por medio de anillitos y ganchos; así parece que esto sucede más en la piedra y en el hierro.

\title{
Claudiano y la APropiación Del VOCABUlario LUCREciano
}

Hasta aquí se presentaron las argumentaciones racionales con las que Lucrecio procuró 'desmitificar' el magnetismo y sus efectos. ${ }^{28}$ No nos detendremos en analizar la persistencia del texto lucreciano durante los siglos posteriores a su producción; no obstante, cabe afirmar al respecto que los gramáticos y los rhetores que enseñaban en las scholae imperiales tardías incorporaron De rerum natura a sus comentarios, aun cuando el acceso al poema resultaba dificultoso. ${ }^{29}$ En consecuencia, si existió un diálogo intertextual entre la poesía lucreciana y la literatura tardoantigua, este se construyó a partir de la puesta en práctica del canon literario, en la continuidad de la tradición escolar. Efectivamente, este diálogo puede ejemplificarse en algunos de los poemas breves que integran los Carmina minora del alejandrino Claudio Claudiano, un corpus de cincuenta y tres composiciones de métrica diversa y contenido variado que habría comenzado a escribir en el año $397^{30} \mathrm{y}$ 
que sería publicado por Estilicón, el magister militum teodosiano y 'hombre fuerte' del Imperio de Occidente, poco después de la muerte del poeta acaecida hacia el $404 .{ }^{31}$

De este conjunto poético, nos ocuparemos del titulado Magnes que ocupa el número 29 (XLVIII) en el orden del corpus. ${ }^{32}$ El poema se inicia con la necesidad de hallar respuestas, 'de-construyendo' la situación comunicativa característica del discurso didáctico, ya que no se trata de un magister que poéticamente se dirige a un discipulus para transmitirle un saber; por el contrario, es el yo lírico quien requiere de la inteligencia de un destinatario doctus, llamado a demostrar cuáles son los resultados de una curiositas inteligenteante los enigmas de la naturaleza: ${ }^{33}$

\section{Quisquis sollicita mundum ratione secutus}

semina rimatur rerum (c. m. 29, 1-2)

Cualquiera que examina el mundo con un razonamiento atento

persiguiendo las semillas de las cosas

hoc mibi quarenti, si quid deprendere veri

mens valet, expediat (c.m. 29, 8-9)

que me explique a mí que pregunto esto, si una mente

está en condiciones de descubrir alguna verdad.

El vocabulario que Claudiano utiliza es el que forjó el propio Lucrecio ${ }^{34}$ para referirse a las partículas indivisibles del antiguo atomismo de Leucipo y Demócrito, que Virgilio y Ovidio utilizaron respectivamente en $B$., V, 32 y M., I, 9- en el marco de sus relatos cosmogónicos: se trata de "las semillas de las cosas" (DRN., I, 59: semina rerum) con las que el poeta epicúreo metaforizó los denominados primordia o corpora prima (DRN., I, 61), es decir, "los elementos a partir de los cuales se generan todas las cosas" que se corresponden con los archai o 'principios' de Epicuro. ${ }^{35} \mathrm{El}$ conocimiento que pueda alcanzarse sobre estos permitiría iluminar las causas de una serie de fenómenos que Claudiano enumera entre los versos 2 y 7 de su poema:

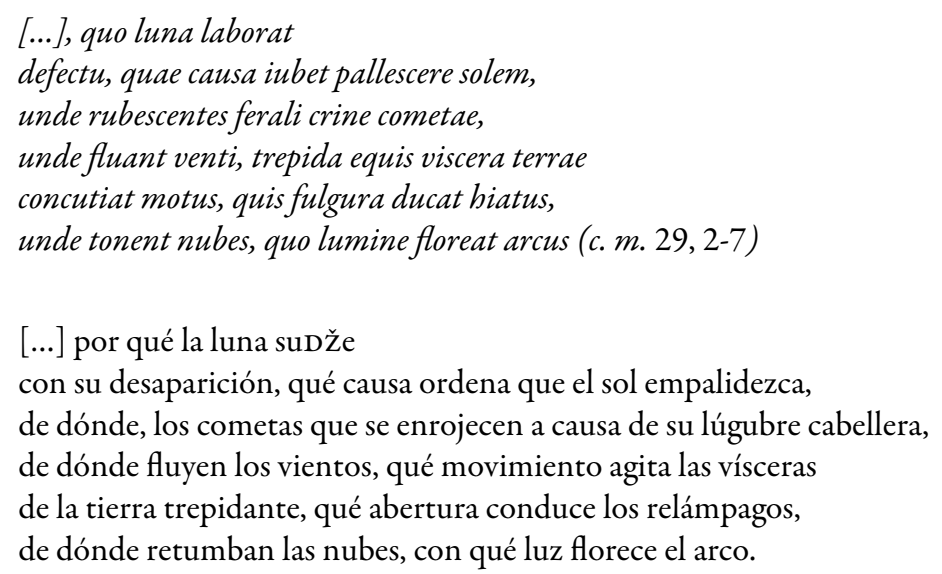

Estos temas se encuentran incluidos entre los contenidos astronómicos y meteorológicos de los libros V y VI de la obra lucreciana: los eclipses de la luna y del sol, el lugar de donde proceden los vientos, los movimientos sísmicos, los relámpagos abriéndose paso en el cielo, el tronar de las nubes y la luz del arco iris; cabe señalar una excepción al respecto: Lucrecio no hace una mención particular de los cometas, tan solo en el L. II, 206-207 alude a "las antorchas nocturnas que vuelan/ por el alto cielo" (nocturnasque faces caeli sublime volantis) y que "extienden sus largos trayectos de llamas" (longos flammarum ducere tractus). 
Asimismo, en una enumeración de meteoros, parafrasea sus propios versos al referirse en el L. V, 1191 a "las errantes antorchas nocturnas del cielo y las llamas voladoras" (noctivagaeque faces caeli flammaeque volantes).

Por su parte, Claudiano también se detiene en otros fenómenos que despiertan asombro, tales como la piedra imán, precisamente, porque nada se destaca en su externalidad - "sin color, oscura y común” (c. $m$. 29, 10: decolor obscurus vilis) - , pero sí por lo maravilloso de sus propiedades que opaca todo tipo de fulgor y de honras, incluyendo el exotismo de lo oriental: ${ }^{36}$

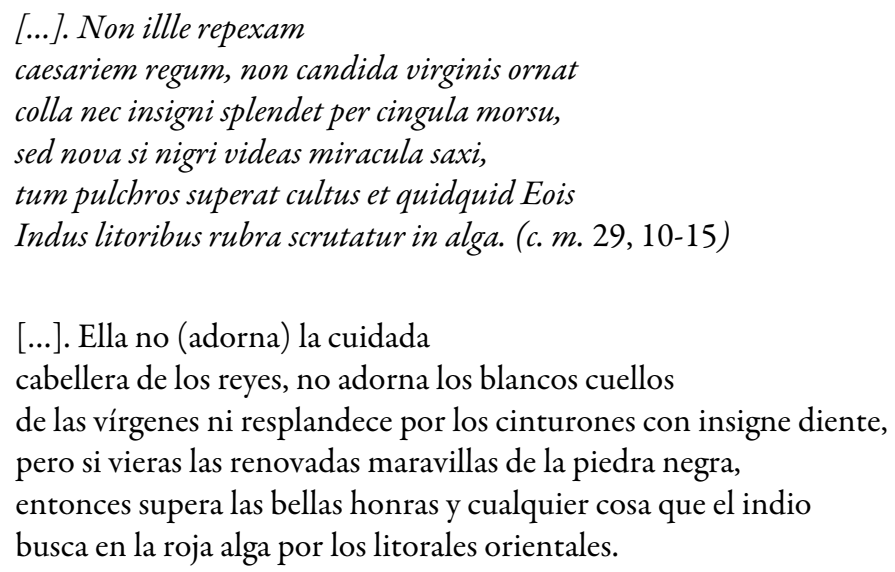

Esta mirada del poeta cortesano hacia lo asombroso, opuesta al racionalismo de Lucrecio, ${ }^{37}$ es congruente con la pasión por las curiosidades del universo advertible entre sus contemporáneos y, a su vez, no resulta ajena a cierta tendencia enciclopedista en la que se pretendía aunar saberes técnicos y humanísticos, como ocurre en muchos de los carmina minora. ${ }^{38}$ Incluso lo maravilloso (miraculosum), aquello que se encuentra en el plano de lo paradójico, deja de pertenecer a los márgenes de lo excepcional para formar parte del inventario de la naturaleza. Estas transformaciones conceptuales comenzaron a operarse desde Plinio el Viejo y su Naturalis Historia (s. I d.C.), cuando integró lo "admirable" a su experiencia científica convirtiendo lo excepcional en "memorable" y, por lo tanto, digno de ser ordenado y conservado. ${ }^{39}$

Para Claudiano, la paradoja del fenómeno magnético se acerca a una forma de simbiosis que los naturalistas denominan 'comensalismo', en la medida en que resulta equivalente a una interacción biológica entre seres de igual o diferente especie donde uno saca provecho de esa asociación sin perjuicio ni beneficio para otro; de ahí que el poeta afirma que la piedra imán, como si se tratara de un organismo vivo que requiere de sustento para conservar su vitalidad y no perecer, se vale del vigor recibido del hierro:

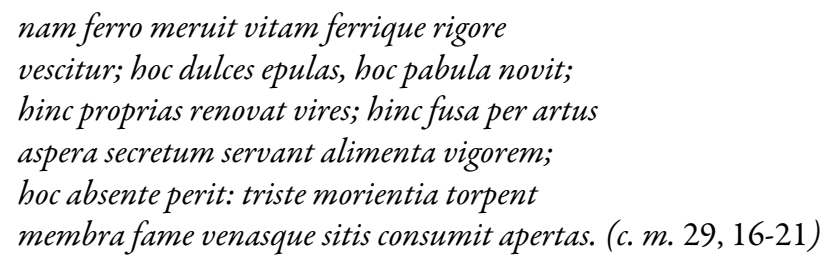

Del contenido de los hexámetros 16-21 se desprende una posible relación con los principios dinámicos de la materia, tal como fueron concebidos en De rerum natura, ya que el cuerpo, puesto en movimiento a 
través de las articulaciones, permite que el esfuerzo de la mente siga conectado a él; ${ }^{40}$ esto mismo ocurre con la distribución de los alimentos a través del cuerpo ${ }^{41}$-incluso el dolor y el placer-, para lo cual en todas las ocasiones Lucrecio recurre al sustantivo artus. ${ }^{42}$ En cuanto al sustantivo membra, Claudiano lo utiliza para referirse a las partes corporales que se entorpecen a causa del hambre y la sed, puesto que es el alimento vital lo que las hace persistir. $\mathrm{Al}$ respecto, Lucrecio afirma que los miembros se animan porque es la vida la que se encuentra en ellos, ${ }^{43}$ y el cuerpo como un vaso contenedor del alma, si se rompe, provoca la salida de la sangre de las venas ${ }^{44}$, mientras, progresivamente, avanzan los signos agónicos de la muerte con la pérdida de la sensibilidad. ${ }^{45}$

\title{
DEL EPICUREÍSMO MATERIALISTA A LA FICCIÓN MÍTICO-ALEGÓRICA
}

Seguidamente y sin mediar conector alguno, Claudiano se traslada al orden de lo mitológico-alegórico para explicar los efectos del magnetismo; para ello recurre a representaciones plásticas y ornamentales de Marte y Venus, a quienes asigna características antinómicas propias del dios de la guerra y de la diosa detentadora de ocios y placeres. ${ }^{46}$ Ambas divinidades, compartiendo un espacio sagrado común, ${ }^{47}$ adquieren la forma figurada del hierro y de la piedra imán, destacándose en él la dureza y en ella la atracción:

\author{
Mavors, sanguinea qui cuspide verberat urbes, \\ et Venus, humanas quae laxat in otia curas, \\ aurati delubra tenent communia templi. \\ Effigies non una deis, sed ferrea Martis \\ forma nitet, Venerem magnetica gemma figurat. (c. m. 29, 22-26)
}

Marte, quien fustiga las ciudades con su sangrienta lanza,

y Venus, que alivia las cuitas humanas por medio del ocio,

poseen altares comunes de un templo dorado.

No hay una imagen única para las divinidades, sino que la férrea figura

de Marte resplandece (y) una joya imantada representa a Venus.

Claudiano ficcionaliza la unión entre el hierro y el imán como una hierogamia o matrimonio sagrado; conforme a lo establecido por los mores, se consagra la unión que asegura la continuidad del sistema sociofamiliar y sostén del orden político de las élites. El poeta, a continuación, incluye loci communes propios del género epitalámico ${ }^{48}$ enumerando ordenadamente algunos momentos de la aristocrática confarreatio. ${ }^{49}$ Estos elementos genéricos comprenden la domum deductio, cortejo de bodas que acompañaba a la novia hacia la casa del novio, la descripción ornamental del atrium donde se llevaba a cabo parte de la ceremonia matrimonialy, en particular, la de la cámara nupcial donde los novios concretaban su amor conyugal: ${ }^{50}$

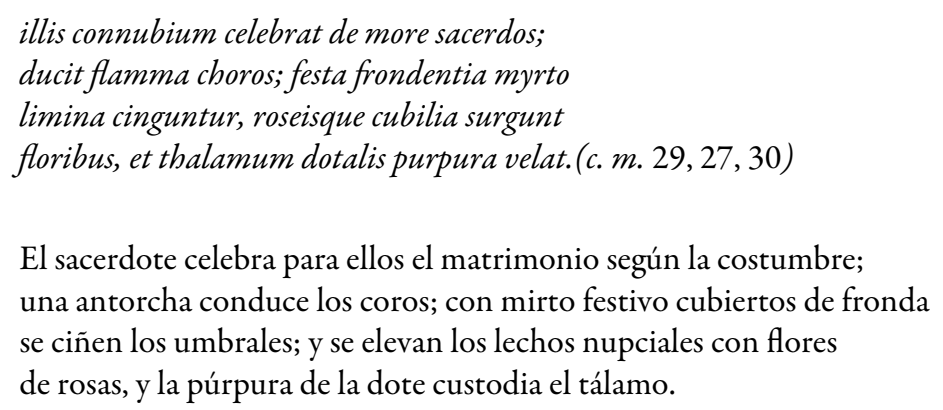

No obstante el cuidado con el que se realiza el ritual, este resulta alterado por un hecho maravilloso (c. $m$. 29,31: mirum opus), dado que se produce una asimetría entre los géneros al ser la diosa, quien, comportándose 
de manera activa, "somete al marido por su propia voluntad" (c. m. 29, 31-32: Cytherea maritum/ sponte rapit). La diosa lo arrastra para atarlo al lecho, así como fuera encadenado en el cielo "a lechos anteriores" ( $c$. m. 29.32: caelique toros priores), según cuenta el vergonzante episodio en el cual un engañado Vulcano expone a la vista de los Olímpicos el modo en que los adúlteros Marte y Venus quedaron atrapados por una red mágica. ${ }^{51}$ Particularmente, Claudiano reelabora la explicación del fenómeno natural a partir de una focalización mitológica de alcances cósmicos, ${ }^{52}$ para lo cual se vale del relato conocido para establecer diferentes niveles entre lo divino y lo humano, ${ }^{53}$ a la vez que fuerza la relación entre los géneros literarios: se suma a lo epitalámico el erotismo elegíaco.

En este punto, Claudiano profundiza su "labor de aguja”, característica de la poesía tardía, pues no solo se vale del recorte y la combinación de elementos provenientes de diferentes géneros, sino que produce un texto nuevo sobre la base de distintos momentos del poema lucreciano. ${ }^{54}$ Por una parte alude al ejemplo de los anillos sostenidos por la atracción del imán (DRN., VI, 911-915) y, por otra, al himno de apertura en el que se invoca a Venus, madre de los romanos y fuerza reproductora de la naturaleza, a quien, en el fragor de las luchas intestinas, Lucrecio reconoce como garante de paz. A continuación, observemos en el subtexto cómo la fiereza marcial es vencida por la suavitas amorosa:

\author{
[...], quoniam belli fera moenera Mavors \\ armipotens regit, in gremium qui saepe tuum se \\ reicit aeterno devictus vulnere amoris, \\ atque ita suspiciens tereti cervice reposta \\ pascit amore avidos inbians in te, dea, visus, \\ eque tuo pendet resupini spiritus ore. (DRN., I, 32-37) \\ [...], ya que Marte, de armas poderosas, \\ rige sobre los feroces oficios de la guerra, quien a menudo en tu regazo \\ se recuesta, vencido por la eterna herida del amor, \\ y así, levantando la mirada con el terso cuello tendido hacia atrás, \\ alimenta miradas ávidas de amor, observándote a ti, Diosa, \\ y el suspiro de él, que se recuesta, pende de tu boca.
}

Así, el texto resultante representa la consumación del conubium:

\author{
pectora lascivo flatu Mavortia nectit \\ et tantum suspendit onus galeaeque lacertos \\ inplicat et vivis totum complexibus ambit. \\ Ille lacessitus longo spiraminis actu \\ arcanis trabitur gemma de coniuge nodis.(c. m. 29, 33-37) \\ encadena los pechos marciales con su aliento sensual \\ y sostiene un peso tan grande y pliega sus brazos \\ al casco y lo rodea por completo con sus vívidos abrazos. \\ Él, excitado por la extensa influencia de su aliento, \\ es arrastrado por nudos misteriosos a partir de la gema consorte.
}

Mientras la naturaleza es la summa rerum que Lucrecio procura iluminar desde la racionalidad, Claudiano insiste en recrear el orden mitológico con aspectos tomados de la realidad humana, convirtiendo a la naturaleza en la acompañante nupcial que asegura el enlace divino: pronuba fit Natura deis (c. m. 29, 38: la Naturaleza es quien conduce a los dioses a la cámara nupcial). Sin embargo, el poeta no puede desentrañar las misteriosas razones que unen a estos objetos como si fueran dos amantes furtivos: subitis sociantur numina furtis (c. m. 29.39: los númenes se asocian en súbitos amores secretos); por ello inquiere retóricamente sobre 
el desconcierto de lo maravilloso, ${ }^{55}$ valiéndose del vocabulario lucreciano en un contexto erótico-elegíaco. Se pregunta, entonces, por el ardor que facilita la persistencia de los pactos entre los metales, la concordia que enlaza dos objetos resistentes, el carácter anhelante de la piedra que hiere a una materia afín por medio del placer amoroso:

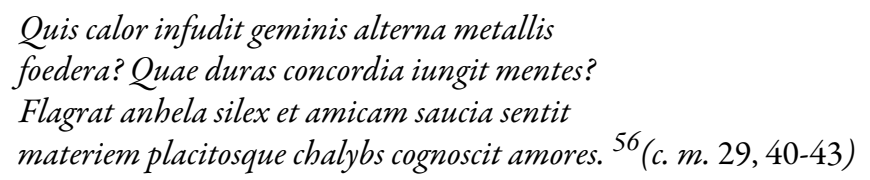

¿Qué calor infundió alianzas mutuas en metales semejantes? ¿Qué concordia une a mentes resistentes? La piedra arde anhelante y siente herida a la materia amada y el hierro reconoce los placenteros amores.

A través de las laudes que exaltan la figura de Venus, en oposición a las imágenes que representan la guerra personificada en Marte, Claudiano, al igual que Lucrecio, glorifica la paz alegorizada en la diosa del amor:

Hunc tu, diva, tuo recubantem corpore sancto circumfusa super, suavis ex ore loquellas funde petens placidam Romanis, incluta, pacem. (DRN., I, 38-40)

Tú, Diosa, te has derramado sobre él, mientras reposa en tu cuerpo sagrado; desde tu boca exhala, gloriosa, suaves palabras buscando la plácida paz para los romanos.

Sola feris occurrit equis solvitque tumorem pectoris et blando praecordia temperat igni. Pax animo tranquilla datur, pugnasque calentes deserat et rutilas declinat in oscula cristas. (c. m. 29, 47-50)

Ella sola se pone en Džente de los fieros caballos, atenúa la inflamación de su pecho y entibia los corazones con un blando fuego.

Una paz tranquila se concede al ánimo y él abandona los combates acalorados e inclina hacia abajo sus crestas rutilantes hacia los besos.

Finalmente, el poema concluye paradójicamente ${ }^{57}$ con la aparente certeza de que no existe otra razón para el fenómeno magnético que las licencias concedidas al dios del amor, a quien el yo lírico interpela: Quae tibi, saeve puer, non est permissa potestas? (c.m. 29, 51: ¿Qué poder no te fue permitido, cruel niño?). ${ }^{58}$ También el amor ha sido objeto de análisis del materialismo lucreciano en De rerum natura IV, 1037-1191, señalándose, entre otras cuestiones, los perjuicios a los que son sometidos los hombres desde lo físico, lo socioeconómico y lo psicológico por causas eróticas. Sin embargo, Claudiano opta por continuar con su intrincado sistema de relaciones míticas para resolver las inquietudes iniciales en torno a los fenómenos meteorológicos; arriba, entonces, a determinadas conclusiones en el marco de un contexto demostrativo o epidíctico en el que exalta la intervención de Amor como fuerza aglutinante de los contrarios. Del poder de sus flechas nada escapa: ni el rayo ni el propio Júpiter Tonante ni las piedras ni los metales, pues su ardor y su capacidad de atracción todo lo impulsan: 
Iam gelidas rupes vivoque carentia sensu membra feris, iam saxa tuis obnoxia telis, et lapides suus ardor agit, ferrumque tenetur inlecebris (c. m. 29, 52-57)

Tú superas al gran rayo y obligas a mugir al Tonante en medio de las olas tras haber abandonado el cielo. Ya hieres las gélidas rocas y los miembros que carecen de una vívida sensibilidad, ya los peñascos están a merced de tus flechas, y su propio ardor lleva adelante a las piedras, y el hierro es retenido por tus tentaciones

\section{Conclusiones}

Ya que la literatura tardía es, por esencia, una póiesis gestada a partir del encuentro de diferentes formas de producción artística, no basta con analizar la relación existente entre la literatura de los siglos anteriores y la producida por poetas como Claudiano para sus contemporáneos cultos, ambas unidas por la continuidad pedagógica de la gramática y la retórica imperiales. Por el contrario, resulta necesario identificar la incorporación de diferentes recursos, incluso, los procedentes de otras artes como los efectos visuales, que convirtieron a esta poesía de carácter cortesano en un sofisticado aparato de creación, donde la mezcla de géneros y de tipos discursivos obliga a la crítica de hoy a estar atenta al polimorfismo del palimpsesto.

En este sentido, advertimos que la estética tardoantigua está sometida a la permanencia de ciertos estereotipos: en el caso del poemita analizado, su sustrato lexical y temático procede del sistema filosófico lucreciano, el cual se inserta coherentemente en el pasado de un epos empedócleo que buscó explicar las leyes de la naturaleza, estableciendo relaciones necesarias entre los elementos. Tal como afirma Farrell, $D e$ rerum natura cuenta con una estructura argumental por la cual cada libro posee por separado unidad e integridad, satisfaciendo una organización arquitectónica sustentada por el desarrollo de la teoría atomista según los principios de la secuencia, el equilibrio, el paralelismo y la inversión. ${ }^{59}$ A partir de este sistema cuidadosamente articulado internamente, Claudiano operó sobre él a través de la variación y la transformación buscando satisfacer otros horizontes de expectativas entre sus receptores, con el fin de diversificar el producto poético resultante.

En cuanto a esta capacidad de intervenir en el texto-base, el poeta tardío fue un deudor de la retórica y de los juegos creativos que convirtieron a las scholae imperiales en talleres de renovación literaria; la intergenericidad como principio de imitación y estimulación a la variedad es lo que se destaca en su poesía, además del refinamiento de las imágenes que lo hizo acreedor de un estilo enjoyado y florido, ${ }^{60}$ acorde con la sofisticación de la corte que constituía su audiencia, quizás nada menos luminosa y colorida que la piedra imán. No obstante, resulta atractiva como una gema para la imaginación, ante la amplificada capacidad de enumerar posibilidades racionales, como las elaboradas por Lucrecio, y por el hecho de ser catalogada entre otras maravillas sin solución.

Y, puesto que procuramos comprender el entramado de este diálogo textual que no se obtura en el Medioevo sino que continúa abriéndose caminos a través del tiempo, cabe detenernos en el oxímoron con el que Claudiano clausuró su breve poema aludiendo a la caprichosa incongruencia de lo amoroso: rigido regnant in marmore flammae (c. m. 29, 57: reinan las llamas en el rígido mármol). Esto resuena en el barroquismo de los opuestos con que Francisco de Quevedo, traduciendo según Dámaso Alonso un soneto del portugués Camoens, ${ }^{61}$ advierte que "Éste es el niño Amor" (v. 12), “es yelo abrasador, es fuego helado" (v. 1). ${ }^{62}$ 


\section{Notas}

1 Los pasajes de De rerum natura que se utilizan en el presente trabajo proceden de la edición de Bailey, C. (ed.), Titi Lucreti Cari, De rerum natura libri sex,3 Vols, Oxford, Clarendon P., 1947. También fue consultada la edición de Munro, H. A. J. (ed.), Titi Lucreti Cari,De rerum natura libri sex,2 Vols., Cambridge University P., 2009 [1864].

2 Lucrecio polemiza sobre las teorías de cuatro exponentes de la filosofía presocrática: Heráclito (I, 635-704), Empédocles (I, 716-829), Anaxágoras (I,830-920) y Demócrito, a quien menciona por su nombre en V, 622. Incluso, en I, 705-715, Lucrecio enumera las diferentes escuelas jónicas de pensamiento, entre las cuales vuelve a insistir en los principios heraclíteos, además de referirse a Anaxímenes, Tales de Mileto y Ferécides de Siro.

3 Cabe señalar que son propias las traducciones de todos los pasajes lucrecianos transcriptos.

4 Cf. Mondolfo, R., El pensamiento antiguo. Historia de la filosofía greco-romana. II. Desde Aristóteles hasta los neoplatónicos, Buenos Aires, Losada, 1974, 95.

5 Farrington, B., La rebelión de Epicuro, Barcelona, Laia, 1983, 23.

6 Farrington, La rebelión, 109.

7 Cf. DRN., V, 6-54.

8 Para este trabajo se consultaron las siguientes ediciones de la obra de Claudiano: Hall, J. (ed.), Claudii Claudiani Carmina. Leipzig, Bibliotheca Scriptorum Graecorum et Romanorum Teubneriana, 1985; Platnauer, M. (ed.), Claudian, I. London, Heinemann, 1922; Jeep, L. (ed.), Claudii Claudiani Carmina, Lipsiae in aedibus B. G. Teubneri, 1876.

9 Acerca del uso de la paradoja en el poema de Claudiano, cf. Hardie, Ph., Classicism and Christianity in Late Antique Latin Poetry, California, University of California Press, 2019, 179.

10 Tal como advierte R. Lavalle, en Referencias naturales en Claudiano. Tesis doctoral Universidad Católica Argentina, Facultad de Filosofía y Letras, 2001, 4-5, consultada el 10 de marzo de 2020,

http://bibliotecadigital.uca.edu.ar/repositorio/tesis/referencias-naturales-en-claudiano.pdf, Claudiano se desenvuelve con la habilidad de un panegirista alabando las maravillas de la naturaleza. No pretende dar explicaciones racionales a la manera de Empédocles, Arato, Lucrecio y Virgilio, sino que expresa su admiración por lo natural de una manera heterogénea, sin generar controversias entre la ciencia y la poesía.

11 Serres, M., El nacimiento de la Física en el texto de Lucrecio. Caudales y turbulencias. Valencia, Pre-Textos, $1994,89$.

12 En Epicuro (Diog. Laer., X, 100), se mencionan las posibles causas de diferentes fenómenos meteorológicos, tales como el torbellino, los relámpagos, entre otros. Cf. Munro, Titi Lucreti Cari, De rerum natura libri sex, vol. II, 378.

13 Cf. Bloch, R., La adivinación en la Antigüedad. México, F.C.E., 2002, 76.

14 Desde el verso 96 al 422, Lucrecio analizó las causas de los siguientes fenómenos atmosféricos: el trueno, el relámpago, el rayo, las tempestades estacionales y la desestimación del origen divino del rayo.

15 Serres, El nacimiento de la Física, 103.

16 El origen de las epidemias se explica también a partir del movimiento de los fluidos; estos pueden distribuirse a través del aire, o bien surgir de la propia tierra. Cf. DRN., VI, 1098-1102.

17 Lucr., DRN., VI, 53-55: propterea quod/ ignorantia causarum conferre deorum/ cogit ad imperium res et concedere regnum (porque/ la ignorancia de las causas los obliga a conferir los hechos/ al imperio de los dioses y a concederles su reino).

18 Existen en la zona del Mediterráneo yacimientos de magnetita, un óxido de hierro particular que presenta un campo magnético remanente y que aparece en forma de una roca de color negro. En cuanto a su nombre, se decía que era procedente de la ciudad de Magnesia, en Lidia, Asia Menor, aunque otras fuentes mencionan la ciudad de Magnesia en Macedonia. Por su parte, Plinio el Viejo, Nat., XXXVI, 25, afirma que su nombre deriva de su descubridor, un pastor del monte Ida, en la región frigia. Por otra parte, Plinio hace referencia a piedras imanes de diferentes cromatismos.

19 Gemelli Marciano, M. L., Democrito e l'Accademia. Studi sulla trasmissione dell'atomismo antico da Aristotele a Simplicio. Berlin-New York, de Gruyter, 2007, 298.

20 Hellegouarc'h, J., Le vocabulaire latin des relations et des partis politiques sous la Republique. Paris, "Les Belles Lettres",1972, 38-40.

21 Serres, El nacimiento de la Física, 122.

22 Markovic, D., The Rhetoric of Explanation in Lucretius' De rerum natura. Leiden-Boston, Brill, 2008, 83.

23 Cf. Markovic, The Rhetoric of Explanation, 84.

24 Markovic, 53.

25 El vacio es una sustancia que se caracteriza por ceder ante cualquier esfuerzo o choque.

26 Cabe entender poro como conducto, vía o intersticio entre las partículas o moléculas que constituyen un cuerpo sólido.

27 El pasaje es considerado oscuro; se trataría de anillos con abundancia de componentes áureos en su exterior y que no se los habría conocido como anillos de hierro. Cf. Sedley, D., Lucretius and the Transformation of Greek Wisdom. Cambridge, Cambridge University Press, 2004, 52-54. 
28 Si bien, en Ion, 533c, Platón se vale del ejemplo de la cadena de anillos que son atraídos por la piedra imán para comparar la fuerza divina que lleva a Ion hablar bellamente sobre Homero, Lucrecio apela a la realidad empírica de los sentidos para analizar el fluir de las sustancias que acuerdan en una juntura necesaria.

29 Cf. Butterfield, D., The Early Textual History of Lucretius' De Rerum Natura. Cambridge, Cambridge University Press, 85.

30 Castillo Bejarano, M. (ed.), Claudiano. Poemas. Vol. I. Madrid, Gredos, 1993, 16.

31 La poesía de Claudiano se habría dividido en tres diferentes corpora: por una parte, De raptu Proserpinae y, por otra, los Carmina maiora integrados por los poemas de ocasión y, a su vez, una tercera rama constituida por los Carmina minora. En cuanto a la posibilidad de que Estilicón hiciera publicar en un volumen unicum la obra del poeta, esto fue rechazado por editores como Birt, Hall y Charlet. Cf. Castaldo, D. (2013). "De flores despojando el verde llano". Claudiano nella poesía barocca, da Faría a Góngora. Napoli, Università degli Studi di Napoli Federico II, 2013, 24,

32 Cf. Hall, Claudii Claudiani Carmina, 376-378. Platnauer, Claudian, I, xxv, señala que existen discrepancias en la numeración y ordenamiento de los Carmina minora.

33 La traducción de todos los pasajes de Claudiano que se transcriben es propia.

34 Lavalle, Referencias naturales, 49, insiste en que Claudiano, para explicar la estructura interna de la materia magnética, debió seguir las huellas lucrecianas.

35 Cf. Bailey, Titi Lucreti Cari, vol. II, 607.

36 Cf. Hardie, Classicism and Christianity, 179.

37 Lavalle, Referencias naturales, 51, sostiene que en este poema Claudiano parece haber seguido la tesis mecanicista lucreciana basada en las corrientes de aire.

38 Cf. Pégolo, L., "Sutilezas narrativas en Poemas breves de Claudio Claudiano", en: Pégolo, L.; Neyra, A. V. (eds.), Un milenio de contar historias. Los conceptos de ficcionalización y narración de la Antigüedad al Medioevo. Buenos Aires, OPFIL, 2016, 96-97.

39 Cf. Conte, G. B., Generi e lettori. Lucrezio, l'elegia d'amore, l'enciclopedia di Plinio. Milano, Arnaldo Mondadori Editore, 1991, 116-118.

40 Cf. $D R N .$, II, 266-268, 271, 283.

41 Cf. $D R N .$, II, 711-713.

42 Cf. $D R N .$, II, 964-965

43 Cf. $D R N .$, III, 120, 127, 245, 276, 283.

44 Cf. $D R N .$, III, 440-442.

45 Cf. DRN., III, 526-547.

46 En la pintura romana y, particularmente, la de la región campana, el motivo de Venus está unido a representaciones elegantes en las que se pone énfasis en los aspectos eróticos, tal como se observa en el mural "La pacificadora Venus desarmando a Marte”, que se encuentra en la "Casa de Marte y Venus”, en Pompeya. Cf. Maiuri, A., The Great Centuries of Painting. Roman Painting. Geneva, Skira, 1953, 77.

47 Zanker, P., en Augusto y el poder de las imágenes. Madrid, Alianza, 1992, 233-234, afirma que, a partir del programa iconográfico del Foro de Augusto, "la estatua de la diosa del amor debía aparecer en toda circunstancia junto a la del dios de la guerra, con lo cual [...] se recordaba necesariamente el amor furtivo de ambos en el mito griego". Más abajo, Zanker recuerda un grupo de figuras de culto, pertenecientes al templo de Mars Ultor, en el que se encuentra el dios de la guerra barbado, con yelmo crestado y clámide, Venus Genetrix junto a Eros y un príncipe augústeo.

48 Claudiano compuso epitalamios como parte de su consagración a la poesía de carácter panegírico, tales como el dedicado a celebrar las bodas del emperador Honorio y la princesa María, y el Carmen minor 25, dedicado a Paladio y Celerina. Ambos están inspirados en la poesía estaciana; al respecto, cf. Wasdin, K., "Honorius Triumphant: Poetry and Politics in Claudian's Wedding Poems”, CP, Vol. 109, N 1 (January), 2014, 48-65, Ramella, T., Claudio Claudiano, Epitalamio per Palladio e Celerina (c.m. 25, Hall). Introduzione, traduzione e commento. Tesi di Recerca. Venezia, Università Ca'Foscari, 2018.

49 En la "Casa de M. Lucrecio Frontón”, correspondiente al denominado cuarto estilo pompeyano (s. I. d.C.), se descubrió un panel en el que se representa una ceremonia nupcial que tiene a Venus como protagonista. Se trata de "El cortejo de Venus y Marte", en el que la diosa tiene el aire meditativo de una joven novia y Marte, vestido con clámide azul y yelmo crestado, se posa sobre la prometida rozándola levemente. Junto a ellos, se encuentran Cupido y un conjunto de mujeres que parece pertenecer a la servidumbre; alguna de ellas podría ser la pronuba. Cf. Maiuri, Roman Painting, 77-78; Senna Garralffoni, R., de Paula Sanfelice, P., "Em tempos de culto a Marte por que estudar Vênus? Repensando o papel de Pompeia durante II guerra”, en: Cerqueira, F., Gonçalves, A. T., Medeiros, E. \& Brandâo, J. L. (orgs.), Saberes e poderes no mundo antigo: estudos ibero-latinoamericanos. Volume I: “Dos Saberes”. Coimbra, Classica Digitalia Universitatis Conimbrigensis (http//classicadigitalia.uc.pt.), 2013, 65-84.

50 Cf. Fedeli, P., Il carme 61 di Catullo. Suizzera, Edizioni Universitarie Friburgo, 1972.

$51 \mathrm{Al}$ respecto, cf. Grimal, P., Diccionario de mitología griega y romana. Barcelona, Paidós, 1984, 11. 
52 Cf. Hardie, Classicism and Christianity, 179.

53 Cf. Coombe, C., Claudian the Poet. Cambridge, Cambridge University Press, 2018, 24.

54 Ware, C., Claudian and the Roman Epic Tradition. Cambridge University Press, 2012, 11, se refiere a tres técnicas alusivas que la crítica advierte en la poesía de Claudiano. Estas son: 1) las citas directas, 2) los "lugares comunes" con empleo o variación del vocabulario tradicional y 3) alusiones menos deliberadas y formales.

$55 \mathrm{Al}$ respecto, cf. Warburg, I., "El correlato poético de la ékphrasis en los Carmina de Claudiano sobre asuntos naturales", Stylos, 16 (16), 2007, 225.

56 Las palabras destacadas se encuentran en el texto lucreciano, cf. Paulson, J., Index Lucretianus. Darmstadt, Wissenschaftliche Buchgesellschaft, 1961.

57 Hardie, Classicism and Christianity, 179, hace referencia a la paradoja final del divino niño Cupido que cuenta con los poderes de un gran dios.

58 Claudiano, en el marco del epitalamio en honor a Honorio y María (Epith., X, 46-47), incluye la figura del travieso Amor como parte del entramado narrativo.

59 Farrell, J. "Lucretian architecture: the structure and argument of the De rerum natura”, en: Gillespie, S.; Hardie, Ph. (eds.), The Cambridge Companion to Lucretius, Cambridge, Cambridge University Press, 2007, 78-79.

60 En cuanto a los refinamientos estéticos tardoantiguos, cf. Roberts, M., The Jeweled Style: Poetry and Poetics in Late Antiquity. Ithaca and London, Cornell University Press, 1989, 38-65.

61 Cf. Blecua, J. M. (ed.), Francisco de Quevedo. Obra poética, T. 1. Madrid, Editorial Castalia, 1969, 533.

62 Se trata del poema amoroso 375 titulado "Soneto amoroso definiendo el amor". 